\title{
Fuerzas armadas y seguridad: Ambivalencia crítica en el México democrático.
}

\section{Armed forces and security: Critical ambivalence in the democratic Mexico.}

\section{AUTORES: Alan Jair García Flores Arturo Miguel Chípuli Castillo}

SUMARIO: I. Introducción. II. Preludio de la inconstitucionalidad de la intervención de las Fuerzas Armadas en funciones de seguridad pública en México. III. Aproximación al concepto seguridad. IV. Modalidades de la seguridad. V.Crítica al análisis constitucional de la jurisprudencia P./J. 38/2000. VI. Reflexiones finales. VII. Fuentes de consulta.

Resumen: La obligación estatal de brindar seguridad a los gobernados, resulta pieza toral dentro de los postulados de un Estado Democrático de Derecho, el cual debe atender a un respeto irrestricto de los derechos fundamentales de quienes deben ser su principal objeto de resguardo, ello implica el diseño de una política criminal alineada a estándares garantistas adoptados a través de las reformas constitucionales de 2008 y 2011. Asimismo, las autoridades legitimadas para participar en funciones de seguridad pública deben ser quienes para tal efecto, posean por imperio de ley facultades para intervenir operativamente, pues participar de facto ocasionaría vulneraciones al plano normativo y a la esfera jurídica de los gobernados.

Palabras clave: Seguridad, derechos humanos, seguridad pública, fuerzas armadas.
Abstract: The State's obligation to provide security for the governed is a fundamental piece within the principles of a democratic state of law, which must attend a strict respect for the fundamental rights of those who should be the main object of its protection, and implies the design of a rights- based criminal policy adopted by the constitutional reforms of 2008 and 2011. Furthermore, only authorized authorities may participate in public security, which means that only the ones that have the power to intervene, by the operation of law, can do it because otherwise it could cause violations to the legal sphere of the governed.

Key words: security, human rights, public security, armed forces.

\section{Introducción}

La seguridad ha sido desde antaño un problema público de vital relevancia para el ser humano, en cuya virtud forja vínculos de protección que permiten congregar esfuerzos para la consecución de las metas.

En esta tesitura, ante la preeminencia de satisfacer sus objetivos para prevenir, controlar y reprimir la criminalidad a través de la política criminal, el Estado 
mexicano en las figuras del ex Presidente Felipe Calderón Hinojosa y el actual Presidente Enrique Peña Nieto, ha apostado por una política de seguridad centrada en el uso de la fuerza contra el narcotráfico que vislumbra la participación de las Fuerzas Armadas en una función de seguridad pública para la que no se encuentran legitimadas para intervenir operativamente y la vulneración a derechos fundamentales como daños colaterales que resientan los gobernados con motivo del empleo de sus acciones en esta modalidad de la seguridad genérica.

La política criminal centrada en el uso de la fuerza contra el narcotráfico ha producido un elevado número de homicidios y quejas ante la Comisión Nacional de Derechos Humanos con motivo de vulneraciones a derechos fundamentales, esgrimidas por las acciones de las Fuerzas Armadas que participan operativamente en funciones de seguridad pública, circunstancia que se contrapone con el tránsito conceptual a nivel normativo adoptado por el Estado mexicano a través de las reformas constitucionales que datan del 2008 y 2011.

\section{Preludio de la inconstitucionalidad de la intervención de las fuerzas armadas en funciones de seguridad pública en México}

Desde sus orígenes, el ser humano ha anhelado su protección, pues al enfrentarse a los diversos fenómenos que lo aquejaban se avocó al incansable deseo de mantenerse a salvo de aquello que le afectara, en cuya virtud, determinó convertirse en sedentario y agruparse para concretar su aspiración proteccionista.

Es posible advertir que la organización política creada por la sociedad, entendida ésta como la "agrupación natural o pactada de personas, que constituyen unidad distinta de cada uno de sus individuos, con el fin de cumplir, mediante la mutua cooperación, todos o alguno de los fines de la vida" (www.rae.es.Consultada el 5 de septiembre de 2015) ha presentado dos importantes momentos de su evolución, la primera y la segunda modernidad. Bajo el esquema de la primera modernidad, el Estado sostenía como sus principales directrices las esferas constitucional y penal, en virtud de ello, la seguridad era concebida como uno de los principales derechos de las personas que se subordinaban al imperio de una entidad jurídica creada para tal efecto, lo cual originaba que se estructurara una relación directamente proporcional a la obligación que tenía el Estado 
como garante estelar de los derechos de sus gobernados, situación que en su momento Rosseau adujo en su obra "El Contrato Social" al advertir que los seres humanos al percatarse de su imperiosa necesidad de organización y dirección, decidieron "ceder" parte de sus derechos a un ente (Estado) que sirviera como depositario de su libertad y a su vez fungiera como principal rector de su actuar.

El esquema clásico de organización se vio superado debido a las nuevas necesidades del hombre, tal es el caso de la llamada globalización, determinada como un proceso complejo que "parte de la integración de mercados y la expansión tecnológica, en el que la regulación política y jurídica se comparte entre actores nacionales y supranacionales, transformándose el tiempo y el espacio de las relaciones sociales, modificando el ejercicio del poder del EstadoNación" (Contreras, 2007: 29).

Este fenómeno llamado globalización marcó en 1990, el inicio de la llamada segunda modernidad, misma que comprende la teoría de la sociedad del riesgo, según la cual, la sociedad se ha tornado catastrófica pues se encuentra asechada por un sinfín de amenazas que la azoran incansablemente colocándola en una encrucijada debido a los terribles riesgos que debe sortear, es por ello que su fin estriba en alcanzar la seguridad. "Aparece el sistema axiológico de la sociedad insegura, [...] o comunidad del miedo [...] dónde no se trata de alcanzar algo bueno sino evitar algo peor [...] es entonces que la solidaridad surge por miedo y se convierte en una fuerza política" (Beck, 2006: 69-70).

Es en razón de la presencia de una sociedad del riesgo que se ocasiona un cambio de organización política de Estados-Nación a Comunidades Objetivas de Amenaza, el cual sólo puede alcanzarse en el marco de una sociedad mundial, en virtud de ello la idea clásica de cumplimiento irrestricto de las obligaciones del Estado para con sus gobernados se ve difuminada al grado tal que en ocasiones es difícil de cumplir y se recurre al empleo de medidas extremas; es el caso del estado de excepción, el cual peligra con convertirse en el estado de normalidad (Beck, 2006).

Es prudente señalar que ante el difícil panorama que enfrentan los Estados debido a las amenazas contra su seguridad, éstos recurren al empleo de lo que Baratta definió como Derecho Penal Simbólico, mismo que se centra en el establecimiento de medidas y preceptos penales para simular que se están llevando a cabo 
acciones en contra de dichas amenazas, aunque en el plano real, los efectos obtenidos no sean del todo positivos (Contreras, 2009). Sin embargo, los resultados-consecuencias del empleo de estrategias tan extremas como el uso del Ejército en funciones de seguridad pública, constituyen un precio sumamente alto que debe pagar la sociedad, la cual ahora tiende a sentirse insegura por las amenazas originales y por los daños colaterales a corto y mediano plazo que ocasionan las acciones empleadas para combatir tales peligros.

El Gobierno Federal encabezado por el Presidente Enrique Peña Nieto, ha mantenido la línea marcada por el ex Presidente Felipe Calderón Hinojosa, sobre la intervención operativa de elementos castrenses para emprender una dura batalla contra el narcotráfico, situación que pone de manifiesto que la política de seguridad del Estado mexicano es definitivamente ineficiente y a su vez, que la violencia ejercida por el Estado mediante la intromisión de las Fuerzas Armadas encargadas de velar por la "seguridad" en el marco de una flamante política de combate a la delincuencia organizada, ha desencadenado una espiral de terror, violencia y muerte, situación que va en detrimento de la consolidación de la democracia, a través del respeto a la norma fundamental y el establecimiento de un gobierno que enaltece el estado de derecho, entendido éste como un Estado en el que las autoridades observan, acatan y respetan el orden jurídico vigente (García, 2004).

Conviene recordar que en el sexenio de Felipe Calderón Hinojosa, la política criminal generó altos índices de violación a derechos civiles y políticos de los gobernados. De tal hecho dan cuenta diversos informes de organismos internacionales como Human Rights Watch y Amnistía Internacional, así como nacionales, tal es el caso de la Comisión Nacional de los Derechos Humanos, quienes en diversos estudios calculan que en el "período que va del 2006 al 2012 el número de desaparecidos fue de aproximadamente 26, 000 personas" (Human Rights Watch, 2013: 136; Amnistía Internacional, 2013: 2) en tanto que los homicidios y las ejecuciones ligadas al combate al narcotráfico "se calculan en 116, 100 personas" para el mismo lapso (Libera, 2012: 7). En este mismo sentido, de 2007 a 2010 la Comisión Nacional de los Derechos Humanos registró un total de "4, 803 denuncias de violaciones a derechos humanos supuestamente cometidos por miembros del ejército en contra de la población civil" (Human Rights Watch, 2011: 7); en este punto, es de interés destacar que el número de arraigos, figura duramente criticada por su diseño e 
implementación en el país, creció de "542 en el 2006 a 1, 896 en 2010" (Amnistía Internacional, 2012: 17) de igual forma, la ONU (2013) en su informe 2013, lo considera como la principal causa de violación de derechos fundamentales.

En tal contexto de violencia, los ciudadanos en México iniciaron manifestaciones clamando por seguridad en el país. Campañas como la de "No más sangre", las dos Marchas Nacionales por la Paz, la Caravana por la Paz encabezada por el poeta Sicilia y el surgimiento de diversas Organizaciones de la Sociedad Civil dirigidas por víctimas de la violencia como la señora Wallace, el señor Martí, el precitado Sicilia, dieron cuenta del grado de desaprobación y frustración social frente a los resultados de la guerra contra el narcotráfico. A ello se sumó la presión que se generó en órganos y en prensa internacional sobre la necesidad de poner atención al clima de violencia que se vivía en el país (Booth, 2012) y obligaron al gobierno de Calderón a replantear la estrategia contra la criminalidad que había venido implementando.

Eduardo Buscaglia (2002) sostiene que una estrategia de combate contra el crimen organizado centrada en el uso de la fuerza se encuentra condenada al fracaso, toda vez que contraviene lo dispuesto por la Convención de las Naciones Unidas contra la Delincuencia Organizada Transnacional, firmada en Palermo, Italia en el año 2000, la cual aconseja evitar el uso de la fuerza por parte de los Estados y a su vez, buscar un pacto con los diversos actores sociales involucrados (partidos políticos).

Lo anterior, se desprende de una decisión unilateral por parte del Ejecutivo Federal avalada erróneamente por la Suprema Corte de Justicia de la Nación (SCJN) quien emitiese una tesis jurisprudencial bajo el rubro Ejército, Armada y Fuerza Aérea. Su participación en auxilio de las autoridades civiles es constitucional (interpretación del artículo 129 de la constitución) que data del 2000, según la cual, ésta se muestra a favor de la participación de los miembros del gremio castrense en funciones de seguridad pública, al esgrimir un sorprendente análisis que dista en demasía de un verdadero estudio jurídico al basarse en simples cuestiones ortográficas, situación que implica no sólo un duro golpe a la legalidad y armonía que constituye el respeto al texto constitucional, sino una pauta para desencadenar una lucha que a simple vista nos coloca dentro de los parámetros de una verdadera sociedad del riesgo. 
A lo largo de estas líneas se demostrará que la intervención de las fuerzas armadas en funciones de seguridad pública en México viola indiscutiblemente el texto constitucional consagrado por los preceptos 21 y 129, en virtud de que el primer numeral sostiene que la seguridad pública es una función a cargo de las instituciones de carácter civil, misma que corresponderá a la Federación, el Distrito Federal, los Estados y los Municipios; mientras que el artículo 129 sostiene que en tiempo de paz, ninguna autoridad militar podrá ejercer más funciones que las que tengan exacta conexión con la disciplina militar.

\section{Aproximación al concepto seguridad}

La aspiración suprema del ser humano ha sido desde antaño, la seguridad, en virtud de la cual se cristaliza un auténtico pacto con sus semejantes dentro de una verdadera vida comunitaria; no obstante, este ideal clásico de un complejo contrato social se ha distorsionado a grado tal que el Estado ha cambiado su forma de actuar para con sus gobernados al considerar como constitucionalmente aceptables ciertas políticas públicas en materia de seguridad en pro de combatir y erradicar las amenazas que atentan contra el orden público, tales como el uso de las fuerzas armadas en el combate al narcotráfico, situación que comprende un panorama por demás preocupante y devastador en razón de los daños colaterales que la población sufre, constituyéndose así en una verdadera sociedad del riesgo.

En aras de comprender en mayor grado las implicaciones y alcances que el vocablo seguridad implica, es necesario remitirse a la voz latina securitas o securitatis que significa seguro o a salvo, es decir, libre de todo riesgo, situación que García (2002) no pasa desapercibida al aseverar que existe un verdadero estado de seguridad cuando se carece de amenazas que socaven, inhiban o supriman los derechos de los gobernados, sin olvidar la indiscutible presencia de condiciones que favorezcan el desarrollo de su propia existencia.

La seguridad comprende un doble aspecto: primeramente, se encuentra el ámbito subjetivo que constituye la confianza de las personas respecto de la protección de sus bienes y derechos frente a las diversas amenazas; y en segundo lugar, desde la perspectiva del campo objetivo donde se localiza el orden jurídico que reside en el llamado poder público (Fernández, 2007).

La seguridad es un indiscutible valor fundante del Estado 
democrático, según lo cual dicha figura jurídica comprende un deslinde de las potestades de los gobernantes emanados de la voluntad popular, así como las libertades de los propios gobernados que expresan sus decisiones a través de la ley, por lo que ésta comprende un elemento de seguridad (García, 2002).

El llamado Estado democrático encuentra su base en dos importantes sucesos de finales del siglo XVIII: la Revolución Americana y la Revolución Francesa, sin embargo, fue precisamente en la Declaración Francesa de 1789 que se estableció concretamente a la seguridad como un derecho natural que el hombre posee por su simple esencia.

La seguridad ha sido consagrada como un valor fundamental en el catálogo supremo de derechos humanos, es decir, en la Declaración Universal de los Derechos Humanos de 1948, misma que en su artículo 3 establece que "todo individuo tiene derecho a la seguridad de su persona", postulado que se complementa a la perfección con los numerales 9.1 y 3 del Pacto Internacional de Derechos Civiles y Políticos, el primero de ellos implica que "todo individuo tiene derecho a la libertad y a la seguridad personal", mientras que el segundo precepto afirma que los Estados miembros de dicho instrumento internacional, se comprometen a garantizar la seguridad y los derechos políticos y civiles.

\section{Modalidades de la seguridad}

La seguridad como aspiración cardinal del hombre, prevé un sinnúmero de acciones para resguardar los valores de máxima importancia a través de acciones estatales o normas jurídicas cuyo contenido tienda a satisfacer dichas necesidades, siempre bajo un irrestricto apego a los derechos fundamentales de los gobernados. De tal suerte, la seguridad no puede versar sobre un todo, motivo por el que es necesario desglosarla en sus diversas modalidades para comprender sus particularidades.

La primera modalidad de la seguridad es la llamada seguridad jurídica, la cual prevé a la seguridad como una verdadera piedra angular de la convivencia social así como parte esencial del Estado moderno a través del Derecho, con lo cual se puede afirmar que tanto el Derecho como el Estado comparten como supuesto inseparable a 
la seguridad jurídica, misma que Delos citado por Fur define como: "la garantía dada al individuo de que su persona, sus bienes y sus derechos no serán objeto de ataques violentos y si éstos llegasen a producirse, le serán aseguradas por la sociedad protección y reparación" (1967: 47).

La segunda modalidad de la seguridad se presenta a través de la llamada seguridad individual, la cual ha constituido una antiquísima aspiración del ser humano, anhelo que estriba en la plena convicción de la protección del hombre siempre que éste respete los derechos de su prójimo, situación que se traduce en una obediencia irrestricta a la esfera jurídica individual de sus semejantes (Fernández, 2007). De tal suerte, el Estado en un esquema proteccionista debe encargarse que las autoridades respeten los derechos y garantías de los gobernados pero de igual forma, debe velar por que los mismos se respeten entre ellos, circunstancia que constituye una verdadera odisea en su actuar.

La tercera modalidad de la seguridad es la denominada seguridad pública, la cual se contempla primeramente como un derecho de los gobernados que se encuentran bajo el imperio de un Estado; sin embargo, dicha modalidad se identifica como una obligación propia del Estado, a través de la cual, el derecho de los gobernados antes señalado podrá cristalizarse. Al respecto Díez citado por Fernández (2007) señala que existe un problema respecto a la seguridad pública, toda vez que es presentada tanto como una función del Estado como un servicio público, situación que en palabras del autor en comento, debe ser aclarado pues la seguridad pública se atribuye al modo originario de manifestación de la soberanía de un Estado, de la cual se desprenden los tres Poderes de la Unión así como sus respectivas características y atribuciones.

La cuarta modalidad es la denominada seguridad nacional, misma que comprende las acciones encausadas por el Estado en función de la salvaguarda de sus órganos e instituciones, frente a los peligros y daños que constituyen las agresiones o movimientos subversivos de naturaleza interna, panorama que implica la intervención de la totalidad de las Fuerzas Armadas permanentes, es decir, del Ejército, Marina y Fuerza Aérea (Brito, 2007).

A decir de lo anteriormente apuntado, se advierte que la seguridad nacional y la seguridad pública constituyen dos funciones de índole pública del Estado, pero el hecho de ser afines, no implica que su contenido base de acción y objeto de protección, sea el mismo, 
pues como bien lo apunta Brito, los encargados de la protección de la seguridad nacional son los miembros de las Fuerzas Armadas, mientras que los titulares de la seguridad pública son las autoridades civiles, circunstancia que consagra el artículo 21 de la Constitución Política de los Estados Unidos Mexicanos.

La seguridad nacional contempla actividades diversas más allá de las estrictamente vinculadas con las tácticas militares, tal es el caso de las acciones concernientes a la construcción e instalación de vías de comunicación, registros públicos, entre otros, razón por la cual Cabanellas (1988) afirma que dicha modalidad de la seguridad constituye el nivel de garantía que el Estado ofrece -mediante la puesta en marcha de actividades políticas, económicas, culturales, sociales y militares- para la protección y cumplimiento de los objetivos nacionales.

La quinta modalidad es la seguridad ciudadana, su objetivo reside en lograr condiciones sociales de civilidad que propicien relaciones pacíficas entre las personas, en razón de ello, es indispensable que el Estado en su conjunto promueva la vigencia de los derechos humanos de los gobernados por una parte, y por la otra, que existan medios adecuados para concretar la participación ciudadana en el diseño, ejecución y evaluación de las políticas públicas de seguridad ciudadana (Rico, 2002).

Conviene señalar que por parte del Estado mexicano también se ofreció una definición de seguridad ciudadana como vía para el combate de la violencia y la delincuencia, bajo la siguiente consideración "el Estado debe garantizar el pleno goce de los derechos fundamentales de los ciudadanos, en particular, de aquéllos que permiten desarrollar y salvaguardar su integridad personal, sus derechos cívicos y el goce de sus bienes" (LPNPSVDPC, 2011: 2).

La sexta modalidad es la denominada seguridad humana, concebida como aquélla cuyo objetivo prioritario tiende a resguardar el pleno goce de los derechos humanos, observados como guía y límite para la intervención del Estado y en particular, de aquéllos principios que garantizan la participación ciudadana, la rendición de cuentas y la no discriminación, así como la salvaguarda de un Estado Constitucional de Derecho y de un estándar mínimo o razonable de bienestar en materia de salud, educación, vivienda, ingreso, etcétera (Olvera, Zavaleta y Andrade, 2012; Carranza, 2005).

La protección integral de la persona implica resguardarla de toda 
amenaza sea de carácter jurídico, económico, social, entre otros, en razón de ello no debe asimilarse con la seguridad ciudadana, puesto que ésta es la especie y aquélla es el género. Así las cosas, un rubro importante de la seguridad humana es la protección contra la violencia a través de la seguridad ciudadana.

Es menester reflexionar sobre el caso del Estado mexicano, sin lugar a dudas delicado, toda vez que su proceso democrático tiene en su contra el hecho que el pueblo, ávido de un cambio de esquema político, determinó apoyar a un partido político distinto al que había venido gobernando durante más de 70 años, no obstante el desencanto que sufrió la sociedad mexicana fue significativo en virtud de que actualmente no sólo existe una crisis económica, sino también escasas oportunidades laborales que originan una mayor inestabilidad política (Fernández, 2007) panorama al que se une un contexto de inseguridad y violencia que fue afrontado por el gobierno federal de Felipe Calderón Hinojosa, para combatir las amenazas a través de la adopción de una política criminal en exceso represiva y con fuertes implicaciones de vulneraciones a derechos humanos de los gobernados, lo cual repercute en la consecución de un Estado Democrático de Derecho en México. De acuerdo con el Informe Latinobarómetro (2013) emitido por la Corporación Latinobarómetro, el porcentaje de aprobación de las políticas de seguridad en México en 2013, fue apenas del $42 \%$, hecho que permite formar una idea de la magnitud del precitado problema que como gobernados es menester afrontar.

En diversos episodios de la vida del Estado mexicano, éste ha recurrido al uso de la fuerza como medio inequívoco para mantener su posición y estabilidad, situación que implica no sólo claras violaciones a derechos humanos sino determinaciones contrarias a las directrices democráticas que intentan seguir. Por esta razón, en aras de reforzar el proceso democrático se ha intentado por diversos medios disminuir el potencial de los aparatos de seguridad en su modalidad pública, ello en pos de frenar el alto índice de violaciones a los derechos fundamentales y en sí mismo, la corrupción que impera en dicha entidad jurídica, intentando así emplear políticas públicas con perspectiva de derechos humanos (Chomsky, 2002).

Lo anterior, se complementa con el hecho crucial que dentro de los rasgos fundamentales de la democracia moderna, no cabe implantar unilateralmente una redefinición de la naturaleza del problema público y su ámbito de resolución, ya que: 
[...] No se puede asumir que el pueblo pague los costos como hacía antes. La gente está dispuesta a ceder el monopolio de la fuerza pero los aparatos de seguridad deben explicar qué hacen y cómo hacen su trabajo. [...] Lo importante es que [...] el Estado no es el único actor que puede decidir en qué ámbito se resuelve la amenaza (Salazar, 2002: 8).

Dentro de la seguridad ciudadana es inadmisible la unilateralidad de decisión del Estado frente a los daños que pueden ocasionarse a los gobernados mediante la implementación de estrategias que combatan a los problemas públicos, pues en el plano actual de la realidad, es posible afirmar que la seguridad ha dejado de ser un tema reservado únicamente al poder ejecutivo, a las personalidades de los aparatos estatales y a las fuerzas armadas (Salazar, 2002); así las cosas, se debe dar paso a la sociedad civil como elemento principal de las políticas públicas con perspectiva de derechos humanos, toda vez que ésta es la que sufrió constantes daños colaterales y repercusiones por la vulneración a sus derechos humanos esgrimida por la política criminal del ex Presidente Calderón y continuada por el gobierno del Presidente Enrique Peña Nieto, en razón de lo cual se ha visto en la imperiosa necesidad de participar más activamente en el plano político de toma de decisiones.

\section{Crítica al análisis constitucional de la jurisprudencia P./J.38/2000}

La Suprema Corte de Justicia de la Nación resolvió la acción de inconstitucionalidad planteada por diputados de la LVI Legislatura Federal, misma que versaba sobre la siguiente controversia:

¿Violan el artículo 21 constitucional las fracciones III y IV del artículo 12 de la Ley General que Establece las Bases de Coordinación del Sistema Nacional de Seguridad Pública que establecen la participación de los secretarios de Defensa Nacional y de Marina en el Consejo Nacional de Seguridad Pública?, ¿Pueden las Fuerzas Armadas auxiliar a las autoridades civiles en materia de seguridad pública en tiempos de paz?, ¿Cuáles son las funciones de las Fuerzas Armadas en tiempo de paz? (http://www2.scjn.gob.mx/ius2006/UnaEj. asp?nEjecutoria $=3534 \& T p o=2$. Consultado el 29 de septiembre de 2015). 
Una vez elaborado el análisis constitucional sobre los artículos vulnerados por las normas de referencia, este Máximo Tribunal Constitucional, resolvió que es constitucionalmente admisible que el Ejército, la Fuerza Aérea y la Armada, actúen durante tiempos de paz en tareas de seguridad pública en auxilio de las autoridades civiles. Pero que ello no puede ser por sí y ante sí, toda vez que se requiere indispensablemente una solicitud expresa, fundada y motivada por parte de aquéllas, a quienes deberán subordinar su actuar y en especial, al orden jurídico comprendido en la Constitución, en las leyes que emanen y en tratados internacionales, de acuerdo con lo sentenciado por el artículo 133 de la Ley Fundamental (Borjón, 2010).

Del análisis esbozado por el Supremo Tribunal de Justicia en México, se desprenden dos argumentos torales que proclamaron infundada la acción de inconstitucionalidad planteada por los diputados de la LVI Legislatura Federal, a saber:

- El artículo 21 constitucional consagra a la seguridad pública como función y responsabilidad del Estado mexicano en su conjunto y no sólo de las autoridades policiales.

- En ningún momento el precepto 21 constitucional señala dependencia u organismo alguno para su inclusión o exclusión, labor que queda a consideración del propio legislador ordinario (Borjón, 2010).

Los argumentos anteriormente señalados, son reforzados por la exposición de motivos de los artículos 21 y 73 fracción XXIII de la Constitución Política de los Estados Unidos Mexicanos, los cuales en su parte nuclear establecen lo siguiente:

[...] La exposición de motivos del artículo 21 constitucional, de fecha 31 de diciembre de 1994, sostiene que ante la creciente capacidad organizativa y movilidad de la delincuencia organizada, el Estado mexicano no debe ni puede hacerle frente mediante una estrategia desarticulada. Es necesario que los tres niveles de gobierno articulen sus potencialidades y compensen sus insuficiencias en materia de seguridad pública.

La corresponsabilidad de cada uno de ellos en un fin común garantiza que el sistema de coordinación que se propone sea verdaderamente un esfuerzo nacional en que los órganos constitucionales que dan cuerpo al federalismo participen con iguales derechos y en condiciones equitativas en la realización de un deber común, garantizar la seguridad y la tranquilidad de 
la población.

Íntimamente vinculado con las ideas reproducidas en la parte de la exposición transcrita, se halla el artículo 73, fracción XXIII de la Constitución, que previene, en forma coherente con lo anterior, que el Congreso tiene entre sus facultades la de expedir leyes que establezcan las bases de coordinación entre la Federación, el Distrito Federal, los Estados y los Municipios, en materia de seguridad pública; así como para la organización y funcionamiento, el ingreso, selección, promoción y reconocimiento de los integrantes de las instituciones de seguridad pública en el ámbito federal (http://www2.scjn.gob. $\mathrm{mx} / \mathrm{ius} 2006 /$ UnaEj. asp?nEjecutoria $=3534 \& T p o=2$. Consultado el 29 de septiembre de 2015).

La SCJN asevera que las Fuerzas Armadas pueden desempeñar funciones de seguridad pública, sin embargo, lejos de aproximarse a tal afirmación, las anteriores transcripciones orientan a la determinación de que la seguridad pública es una función a cargo del Estado mexicano en su conjunto, situación que en ningún momento implica que dichas autoridades puedan llevar a cabo labores propias de esta modalidad de la seguridad genérica.

Corcuera (1999) coincide con la SCJN en lo tocante a la determinación que la propia Ley Fundamental faculta al legislador para señalar las autoridades de los tres niveles de gobierno que deben coordinarse para atender las acciones propias de la seguridad pública, sin embargo, dicho autor considera éstas deben estar legitimadas para ejecutar tales funciones. Situación que se agrava cuando el propio Tribunal Constitucional omite conceptualizar a la seguridad pública, término que dicho sea de paso, no se encuentra determinado por la propia Ley Fundante, razón por la cual ésta asevera que la seguridad pública como función no es exclusiva de los cuerpos policiacos.

La SCJN aseguró en su excelso análisis jurídico que el último párrafo del precepto 21 del Código Supremo, se encuentra "separado por un punto y aparte del que se refiere a los principios que rigen la actuación de las instituciones policiales, por lo que bajo esa circunstancia no cabe identificar a la Federación, el Distrito Federal, los Estados y los Municipios, exclusivamente con autoridades policiacas" (http:// www2.scjn.gob.mx/ius2006/UnaEj.asp?nEjecutoria=3534\& $\mathrm{Tpo}=2$. Consultada el 29 de septiembre de 2015).

El argumento anterior, resulta particularmente familiar al que 
formulara en el mismo sentido Antonio Lozano Gracia, Procurador General de la República, a saber:

I. Es principio general que donde la ley es clara no debe ser interpretada.

II. El artículo 21 constitucional comprende dos hipótesis normativas: una referida a la seguridad pública como una función a cargo del Estado y otra que establece los principios a que debe sujetarse la actuación policial. Esta diferencia se plantea cuando el quinto párrafo del artículo 21 constitucional señala, en primer lugar, que la seguridad pública es una función a cargo de la Federación, del Distrito Federal, de los Estados y los Municipios, es decir, declara que la seguridad pública es una función del Estado mexicano en todos sus órganos de gobierno. Hasta aquí debe distinguirse esta disposición constitucional. Después de un punto y seguido, agrega en otro contenido normativo, que la actuación de las instituciones policiales se regirá por los principios de legalidad, eficiencia, profesionalismo y honradez (http://www2.scjn.gob.mx/ius2006/ UnaEj.asp?nEjecutoria=3534\&Tpo=2, fecha de consulta: 29 de septiembre de 2015).

Lo antes vertido, resulta por demás cuestionable y a todas luces alejado de un verdadero análisis jurídico, puesto que si bien el propio artículo 21 constitucional no señala explícitamente a alguna autoridad en específico, si incorpora a los cuerpos policiales de manera inmediata posterior al establecimiento de la seguridad pública como función a cargo de los tres niveles de gobierno, ello a través de la explicación de los principios rectores de las instituciones policiales, lo que debe interpretarse como una función a cargo de estas corporaciones.

A decir de Borjón (2010), la seguridad pública como función implica la incidencia de diversas autoridades, sin embargo, tal situación no establece que éstas posean funciones específicas de seguridad pública, lo anterior se complementa con la exposición de motivos de la SCJN, al señalar que "la coordinación que se busca incluye a todas las autoridades que directa o indirectamente tienen facultades constitucionales y legales relacionadas con la seguridad pública" (http:// www2.scjn.gob.mx/ius2006/UnaEj.asp?nEjecutoria=3534\&Tpo=2. Consultada el 29 de septiembre de 2015).

Corcuera (1999), sostiene que el concepto de seguridad pública y en sí, la explicación de sus rasgos esenciales no es localizado 
dentro del numeral 21 constitucional, ni tampoco, en la Ley General que Establece las Bases de Coordinación del Sistema Nacional de Seguridad Pública, razón por la cual debe auxiliarse en otros ordenamientos, tal es el caso del Código Penal Federal, mismo que consagra a la seguridad pública como bien jurídico tutelado, a través de su Libro Segundo, Título Cuarto, conformado por los delitos de evasión de presos, quebrantamiento de sanciones, portación de armas prohibidas y asociaciones delictuosas.

La SCJN omitió establecer el concepto de seguridad pública, del cual adolece el propio artículo 21 dela ConstituciónFederal, situación que produce confusión y brinda la pauta para afirmar de forma equivocada que esta modalidad de la seguridad puede ser llevada a cabo por autoridades militares.

La seguridad pública es catalogada por el precepto 21 constitucional como una función a cargo de los tres niveles de gobierno, sin embargo, dicho artículo no explica en qué consiste, circunstancia que tampoco aclara el Máximo Tribunal Constitucional en México, razón por la cual Borjón (2010) recurre a la Ley de Seguridad Pública del Distrito Federal, misma que en sus artículos 2 y 3, proporciona bases importantes para disipar esta complicación.

La seguridad pública según el ordenamiento antes señalado, es una función exclusiva del Estado mexicano y tiene por objeto:

I. Mantener el orden público;

II. Proteger la integridad física de las personas así como sus bienes;

III. Prevenir la comisión de delitos e Infracciones a los reglamentos gubernativos y de policía;

IV. Colaborar en la investigación y persecución de los delitos, y

V. Auxiliar a la población en caso de siniestros y desastres.

Estas funciones se entienden encomendadas al Departamento y a la Procuraduría, de acuerdo a la competencia que para cada uno de los cuerpos de seguridad pública establece la Constitución Política de los Estados Unidos Mexicanos (Art. 2 de la Ley de Seguridad Pública del Distrito Federal).

Se puede aseverar que todas y cada una de las tareas que se señalan para la seguridad pública son propias para salvaguardar a 
las personas, sus bienes, las instituciones políticas y democráticas y en sí, para el respeto a la ley, las cuales se encuentran conferidas por disposición del propio numeral citado, al departamento del Distrito Federal y a la Procuraduría General de Justicia del Distrito Federal, ello mediante los Ilamados cuerpos de seguridad pública, mismos que son definidos por el artículo 3 del citado cuerpo legal en comento:

Para los efectos de esta ley, se entenderá por:

$[\ldots]$

I. Policía del Distrito Federal: a la Policía Preventiva y la Policía Complementaria del Distrito Federal;

VII. Policía Judicial: a la Policía Judicial del Distrito Federal, y

VIII. Cuerpos de Seguridad Pública: a las corporaciones a que se refieren las fracciones VI y VII de este artículo (Art. 3 de la Ley de Seguridad Pública del Distrito Federal).

Este esquema de organización encuadra dentro de lo dispuesto por el artículo 21 constitucional, el cual invoca a los cuerpos policiacos dentro de su estructura, circunstancia que permite reflexionar acerca de la titularidad de estos respecto a las labores de seguridad pública, no así a losmiembros castrenses como equivocadamente sostiene la SCJN.

Corcuera (1999) plantea que los argumentos esgrimidos por los diputados de la LVI Legislatura Federal, están en sí equivocados, toda vez que la Ley General que Establece las Bases de Coordinación del Sistema Nacional de SeguridadPública no contravienea la Carta Magna, en virtud de que su objeto estriba en coordinar a las dependencias que cuentan con cuerpos policiacos, y con otras autoridades cuyas funciones inciden en el servicio de seguridad pública, tales como las Secretarias de la Marina y de la Defensa Nacional, sin embargo, ello no implica que las referidas autoridades posean facultades para llevar a cabo funciones de seguridad pública, esto con excepción de los cuerpos policiales, en razón de lo cual, la Suprema Corte acierta en su análisis al señalar que "el Consejo Nacional de Seguridad Pública no es una instancia que modifique la competencia constitucional" (http:// www2.scjn.gob.mx/ius2006/UnaEj.asp?nEjecutoria=3534\&Tpo=2. Consultada el 29 de septiembre de 2015).

La Ley General que Establece las Bases de Coordinación del Sistema Nacional de Seguridad Pública, debió haber sido interpretada 
en sentido estricto para las autoridades que poseen por disposición constitucional facultades para llevar a cabo funciones de seguridad pública, es decir, a los cuerpos policiales, y aquéllas que de forma indirecta inciden en la seguridad pública, más no a otra clase de funcionarios. Por tal razón, cuando la ley en comento se refiere a las autoridades competentes o aquéllas que en razón de sus atribuciones contribuyen con el objeto de seguridad pública, se aboca en primer lugar, a la policía; mientras que en segundo plano, considera a las autoridades que inciden en labores de la seguridad pública, más no que en sí lleven a cabo funciones de esta modalidad (Corcuera, 1999; Borjón, 2010).

El principio de legalidad es el postulado nuclear del sistema jurídico mexicano, en virtud del cual, las autoridades no pueden ir más allá de las facultades que por ministerio de ley les fueron conferidas, de tal suerte, tanto la Secretaría de la Defensa Nacional como la Secretaría de la Marina y la Armada de México pueden participar en las labores de coordinación de la función de seguridad pública, pero de ninguna forma, tienen legitimación para realizar operativos que le competen a los cuerpos policiacos, por ser éstos titulares de las misiones de seguridad pública en México.

Los diputados de la LVI Legislatura Federal no estructuraron bien el análisis de su acción de inconstitucionalidad, toda vez que las fracciones III y IV de la Ley General que Establece las Bases de Coordinación del Sistema Nacional de Seguridad Pública no son violatorias del artículo 129 de la Ley Fundamental, pues a decir de Borjón (2010), las Secretarías de la Defensa Nacional y de la Marina poseen funciones que van más allá de las militares, pero esto bajo ninguna circunstancia implica que posean de jure facultades para llevar a cabo atribuciones propias de la seguridad pública. Los despachos en referencia, comprenden autoridades militares y no militares, las primeras -de acuerdo al artículo 129 constitucional- no pueden inmiscuirse en labores que no tengan exacta conexión con la disciplina militar; mientras que las segundas, si pueden incidir en actividades de la seguridad pública.

El artículo 129 del ordenamiento supremo establece claramente que:

"En tiempo de paz, ninguna autoridad militar puede ejercer más funciones que las que tengan exacta conexión con la disciplina militar. Solamente habrá Comandancias Militares fijas y permanentes en los castillos, fortalezas 
y almacenes que dependan inmediatamente del Gobierno de la Unión; o en los campamentos, cuarteles o depósitos que, fuera de las poblaciones, estableciere para la estación de las tropas (Art. 129 de la Constitución Política de los Estados Unidos Mexicanos)."

Para entender los alcances del numeral en comento, basta con abocarse a la interpretación literal del texto, el cual es en sumo grado claro, toda vez que las autoridades militares no podrán en tiempo de paz, realizar más funciones que las que posean exacta vinculación con la llamada disciplina militar, misma que a decir de Corcuera (1999) debe entenderse primeramente, como la sujeción de los elementos de los institutos armados a los lineamientos para mantener el orden y la subordinación de éstos; mientras que en segundo lugar, debe considerarse la profesión del arte de las armas con la finalidad de conservar a los militares competentes para llevar a cabo su principal misión: el combate.

En relación con lo antes aseverado, cabe puntualizar lo concerniente a los militares de armas, los cuales son definidos por la propia Ley Orgánica del Ejército y Fuerza Aérea Mexicanos, como aquéllos que "[...] técnicamente se educan para el mando, adiestramiento y conducción de Unidades de Combate; su carrera es profesional y permanente. Para los efectos de esta Ley, en la Fuerza Aérea, los pilotos aviadores pertenecen a esta clase" (Art. 134 de la Ley Orgánica del Ejército y Fuerza Aérea Mexicanos).

Considerando el texto citado, se puede vislumbrar una prohibición expresa para los militares de armas, puesto que si la carrera de éstos es una formación para el mando, adiestramiento y conducción de unidades de combate de naturaleza permanente, ello implica que dichos elementos armados no pueden en ningún momento, atender otras funciones que no posean dentro de su estructura, una vinculación exacta con la propia disciplina militar.

La SCJN otorgó dentro de su análisis constitucional, una interpretación completamente diferente y por demás desvinculada a la realidad jurídica que dicho precepto fundamental consagra, al señalar tajantemente que,

[...] Las funciones que tienen exacta conexión con la disciplina militar a las que se refiere el artículo 129, van más allá de las labores internas de la vida militar [...] dentro de las cuales se encuentra auxiliar a las autoridades civiles con el uso de la fuerza de la que disponen en actividades relacionadas 
directa o indirectamente con la seguridad pública (http://www2. scjn.gob.mx/ius2006/UnaEj. asp?nEjecutoria $=3534 \& T p o=2$.

Consultado el 29 de septiembre de 2015).

Respecto al argumento esgrimido por este Máximo Tribunal Constitucional, Corcuera (1999) afirma que la labor de la SCJN, respecto a su tergiversación del precepto 129 constitucional es por demás sorprendente, puesto que no sólo interpretó más allá del propio texto constitucional, sino que formuló una contradicción excelsa al concluir que las funciones que tienen exacta vinculación con la disciplina militar no tienen por ello una exacta trabazón con la misma disciplina marcial.

El resultado anterior se produjo del análisis del artículo 89 fracción VI de la Ley Fundamental, según el cual, el Presidente de la República en su carácter de Jefe Supremo de las Fuerzas Armadas puede disponer de la totalidad de éstas para la protección de la seguridad interior, situación que se refuerza con el texto del mismo artículo 119 constitucional, el cual determina que "los Poderes de la Unión tienen el deber de proteger a los Estados contra toda invasión o violencia exterior. En cada caso de sublevación o trastorno interior" (Art. 119 de la Constitución Política de los Estados Unidos Mexicanos).

Hasta este preciso momento, la SCJN no se ha pronunciado respecto a la homologación o diferenciación de los conceptos seguridad pública y seguridad interior, sin embargo, a decir de Borjón (2010), este Máximo Tribunal ha optado por considerarlos como sinónimos, cuando en realidad no lo son, toda vez que la paz interior es un bien jurídico; mientras que la seguridad pública, es en un sentido, un bien jurídico y, en otro, una función.

Dentro de los apartados del segundo capítulo de la presente investigación, se determinó que el concepto de seguridad interior, no era establecido por el propio artículo 89 fracción VI de la Ley Fundamental, sin embargo, para tal cometido, se recurre a diversos ordenamientos jurídicos que sirven de complemento para otorgar una definición del mismo, o al menos, una aproximación a éste. Es particularmente el caso del Código de Justicia Militar, el cual comprende en su Libro Segundo, Título Séptimo, un apartado contra la seguridad interior, dónde se distinguen dos importantes delitos: la sedición y la rebelión.

Al tenor de las anteriores consideraciones, el Presidente de la República podrá hacer uso de la totalidad de las Fuerzas Armadas, tal 
y como lo establece el propio numeral 89 fracción VI de la Constitución Federal, es decir, sólo en los casos de sedición y rebelión, situación que se complementará con lo estipulado por el precepto 119 constitucional y el 128 fracción IV del Código de Justicia Militar (Corcuera, 1999).

El segundo ordenamiento en recurrirse para determinar las particularidades de la seguridad, es el Código Penal Federal, mismo que en su Libro Segundo consagra los llamados delitos contra la nación, dentro de los cuales se encuentran los siguientes tipos penales: Traición a la Patria, Espionaje, Motín, Terrorismo, Sabotaje y Conspiración. Situación ante la cual se infiere que la seguridad interior es en sí, un género de los delitos contra la seguridad nacional, toda vez que el propio Código de Justicia Militar coincide con el Código Sustantivo Federal en materia Penal, en los delitos de rebelión y sedición, sólo que para este último ordenamiento, ambos delitos se consolidan como tipos penales contra la seguridad interior, razón por la cual se concluye que estos dos son en sí, un género de los delitos contra la seguridad nacional (Borjón, 2010).

Por cuanto hace al narcotráfico, éste no ha sido catalogado como un delito contra la seguridad nacional, razón por la cual, aun cuando sea de facto una amenaza contra la referida modalidad de la seguridad, de jure no lo es, situación que implica que el decreto por el cual el Presidente de la República hace uso de las Fuerzas Armadas para combatir al narcotráfico es por demás, contrario a las disposiciones constitucionales consagradas por los artículos 21 y 129 de la Carta Magna. En tal virtud, a la Suprema Corte no le asiste la razón cuando afirma que el narcotráfico "no es sólo un problema de seguridad pública, sino de seguridad interior" (http://www2.scjn.gob.mx/ius2006/ UnaEj.asp? nEjecutoria=3534\&Tpo=2. Consultado el 29 de septiembre de 2015).

\section{Reflexiones finales}

Al ceñir de este sencillo análisis jurídico respecto a los argumentos que sirvieron de base para la resolución emitida por la Suprema Corte de Justicia de la Nación, puede determinarse que si bien es cierto, los argumentos esgrimidos por los diputados de la LVI Legislatura Federal, no fueron planteados correctamente, ello no representa justificación alguna para que el Máximo Tribunal Constitucional 
haya creado una resolución basada en un análisis jurídico falto de apreciaciones fundamentales e interpretaciones adecuadas respecto de preceptos constitucionales que son claros bajo una interpretación literal, provocando ambigüedad para la determinación de las funciones de una institución tan importante para México como lo son las Fuerzas Armadas, ocasionándole descredito frente a la población por su participación en funciones de seguridad pública para las cuales de jure no están legitimados.

La magnitud del poder que ostenta la SCJN es excelsa y por lo tanto, delicada, toda vez que una determinación errónea basada en argumentos infundados y oscuros, permitió la emisión de un decreto inconstitucional que albergó el malentendido ego de un mandatario federal y la continuación de una política criminal basada en el uso de la fuerza para combatir al narcotráfico, quienes en su afán de demostrar su poderío ordenaron la inmediata participación de las fuerzas marciales en labores propias de la seguridad pública, ocasionando con ello, la transformación de México en un verdadero campo de batalla, el cual forjó sus cimientos en flagrantes vulneraciones a derechos fundamentales e incalculables muertes.

En esta tesitura, es menester reflexionar si la determinaciones esgrimidas a través del diseño de política criminal del Presidente Enrique Peña Nieto, heredada por su antecesor, basadas en el uso de la fuerza para combatir al narcotráfico resultan pertinentes para satisfacer el delicado problema público que aqueja al Estado mexicano sin incurrir en vulneraciones a derechos fundamentales que coloquen al gobernado dentro de los postulados de una sociedad del riesgo.

Amnistía Internacional. (2013). Enfrentarse a una pesadilla. La desaparición de personas en VII. Fuentes de consulta México. Reino Unido: Autor.

Beck, U. (2006). La sociedad del riesgo. Hacia una nueva modernidad. España: Paidós.

Booth,W.(2012). Mexico'scrimewavehas leftabout 25,000 missing, government documents show. Washington post. http://articles.washingtonpost. com/2012-11-29/world/35584943_1_mexico-citymexican-government-human-rights. ${ }^{-}$Consultado el 29 de septiembre de 2015. 
Borjón Nieto, J. J. (2010). Lucha contra el crimen consulta organizado: fracaso de la militarización. Letras jurídicas. (11) (21). México.

Brito Checchi, M. R. (2007). "Del régimen jurídico de la seguridad jurídica 0 , antes bien, de la inseguridad del régimen jurídico de la seguridad pública ¿Cuestión de compromiso?" en Cisneros Farías, G.; Fernández Ruíz, J. y López Olvera, M. A. (Coord.). (2007). Seguridad Pública. Segundo Congreso Iberoamericano de Derecho Administrativo. México: UNAM.

Buscaglia, E.; González Ruíz, S.; Fumarulo, S. y C. Prieto Palma. (2002). Delincuencia organizada y terrorismo. Su combate a través de la Convención de Palermo. Revista Universitaria de la Universidad Católica de Chile. Delincuencia Organizada y Corrupción. (1) (1). México.

Cabanellas de Torres, G. (1988). Diccionario jurídico militar. Buenos Aires: Heliasta.

Carranza, E. (2005). "Situación del delito y de la seguridad de los habitantes en los países de América Latina" en Carranza, E. (Coord.). (2005). Delito y seguridad de los habitantes. $2^{\mathrm{a}}$ ed. México: Siglo XXI Editores.

Chomsky, N. (2002). El nuevo humanismo militar. Lecciones de Kosovo. México: Siglo XXI Editores.

Código de Justicia Militar.

Constitución Política de los Estados Unidos Mexicanos.

Contreras López, R. E. (2009). Derecho Penal: Parte General. México: Universidad Veracruzana, Códice.

Contreras López, R. E. y M. E. Contreras López. (Coordinadoras). (2007). Derecho Penal y globalización. ¿Un cambio de paradigma?. México: Universidad Veracruzana, Conacyt, 
Arana Editores.

Corcuera Cabezut, S. (1999). "Propuesta de una iniciativa para retirar a las fuerzas armadas de las funciones de seguridad pública" en Sierra Guzmán, J. L. (Coordinador). (1999). EI Ejército y la constitución mexicana - Combate al narcotráfico, paramilitarismo y contrainsurgencia. $2^{\mathrm{a}}$ ed. México: Plaza y Valdés.

Corporación Latinobarómetro. (2013). Informe Latinobarómetro 2013. Chile: Autor. Disponible en www.latinobarometro.org/documentos/LATBD INFORME_LB_2013.pdf. Consultado el 29 de septiembre de 2015.

Declaración Universal de los Derechos Humanos.

Fernández Ruíz, J. (2007). "Reflexiones en torno a la seguridad" en Cisneros Farías, G.; Fernández Ruíz, J. y López Olvera, M. A. (Coord.). (2007). Seguridad Pública. Segundo Congreso Iberoamericano de Derecho Administrativo. México: UNAM.

Fur, L. L. (1967). Los fines del Derecho. $4^{\mathrm{a}} \mathrm{ed}$ Trad. D. Kuri Breña. México: UNAM.

García Maynez, E. (2004). Introducción al Estudio del Derecho. 57 ed. México: Porrúa.

García Ramírez, S. (2002). "En torno a la seguridad pública -Desarrollo penal y evolución del delito-" en Peñaloza, P. J. y M. A. Garza Salinas. (2002). Los desafíos de la seguridad pública en México. México: Instituto de Investigaciones Jurídicas, PGR, Universidad Iberoamericana.

http://www2.scjn.gob.mx/ius2006/UnaEj. asp?nEjecutoria $=3534 \& T p o=2$, fecha de consulta: 29 de septiembre de 2015.

Human Rights Watch. (2011). Ni seguridad, ni derechos. Ejecuciones, desapariciones y tortura en la "guerra contra el narcotráfico" de México.
VII. Fuentes de consulta 
VII. Fuentes de consulta

EUA: Autor.

Human Rights Watch. (2013). Los desaparecidos de México. El persistente costo de una crisis ignorada. EUA: Autor.

Ley de Seguridad Pública del Distrito Federal.

Ley Orgánica del Ejército y Fuerza Aérea Mexicanos.

Líbera. (2012). México: la guerra invisible. Historias, cifras y negocios de los carteles criminales y la impunidad de las mafias mexicanas. Disponible en: http://cauceciudadano. org.mx/CAUCEDESCARGAS/Dossier_LIBERA Mexico_La\%20Guerra_Invisible.pdf. Consultadō el 29 de septiembre de 2015.

Lineamientos de la Política Nacional de Prevención Social de la Violencia, la Delincuencia y la Participación Ciudadana.

Olvera Rivera, A.; Zavaleta Betancourt, A. y V. Andrade Guevara. (2010). Veracruz en crisis. La sociedad civil realmente existente: corporativismo sindical y campesino, movimientos indígenas y actores civiles. Vol. IV. México: Universidad Veracruzana, Editora del Gobierno del Estado de Veracruz, CONACyT, FOMIX.

ONU. (2013). Examen Periódico Universal. Ginebra: Autor.

Pacto Internacional de Derechos Civiles y Políticos.

Rico, J. M. y L. Chinchilla. (2002). Seguridad ciudadana en América Latina. Hacía una política integral. México: Siglo XXI Editores.

Salazar, A. M. (2002). Seguridad nacional hoy. Reto de las democracias. México: Nuevo Siglo.

www.rae.es. Consultada el 5 de septiembre de 2015. 